\title{
The National Map: New Viewer, Services, and Data Download
}

\section{Introduction to the New Viewer and Services}

Managed by the U.S. Geological Survey's (USGS) National Geospatial Program, The National Map has transitioned data assets and viewer applications to a new visualization and product and service delivery environment, which includes an improved viewing platform, base map data and overlay services, and an integrated data download service.
This new viewing solution expands upon the National Geospatial Intelligence Agency (NGA) Palanterra X3 viewer, providing a solid technology foundation for navigation and basic Web mapping functionality. Building upon the NGA viewer allows The National Map to focus on improving data services, functions, and data download capabilities. Initially released to the public at the 125 th anniversary of mapping in the USGS on December 3, 2009, the viewer and services are now the primary distribution point for The National Map data.

The National Map Viewer: http://viewer.nationalmap.gov
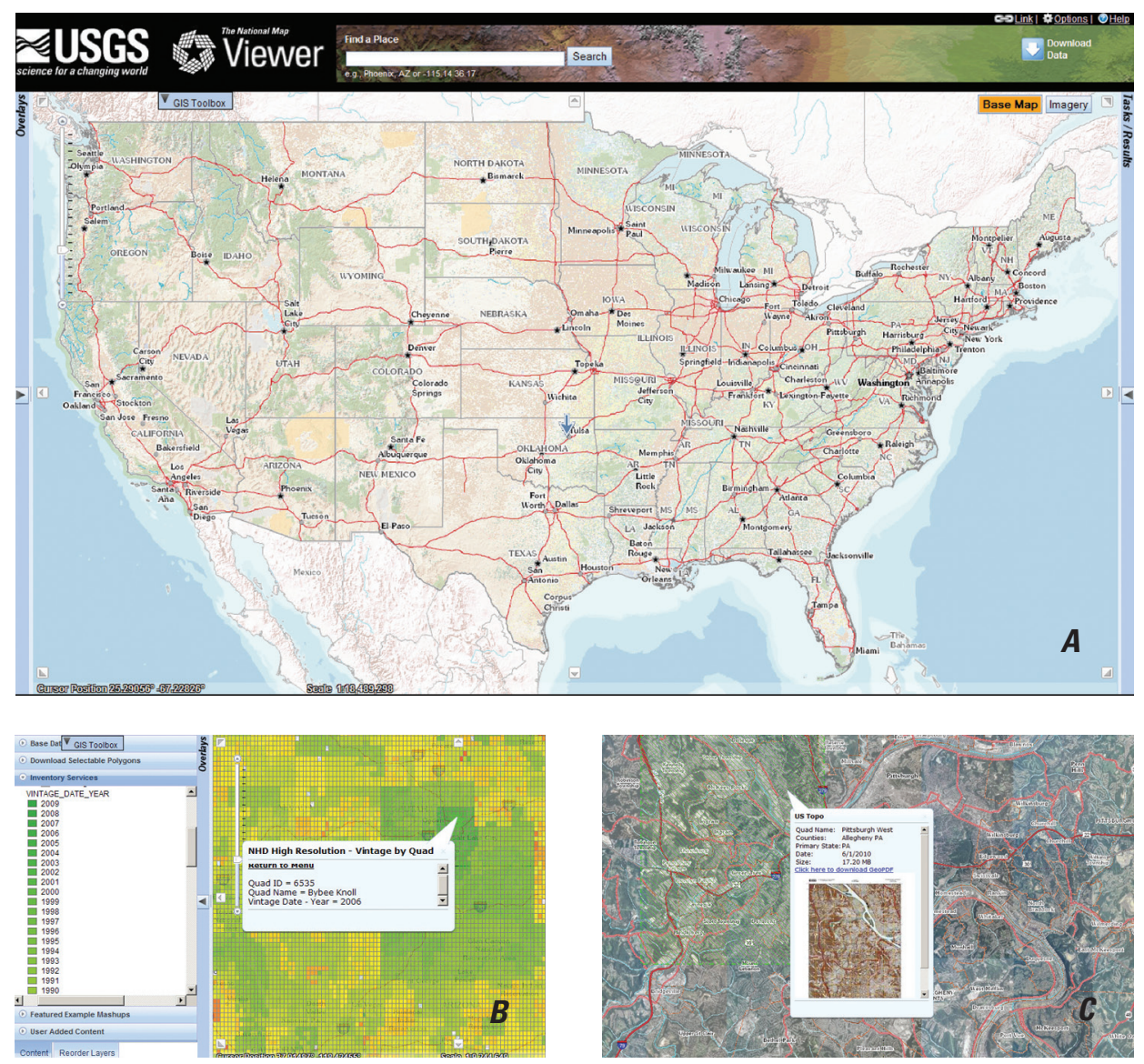

\section{Key Features of the Viewer}

- Fast, cartographically designed base map services using datasets from the National Atlas of the United States ${ }^{\circledR}$ and The National Map

- GIS tools are included to identify features, change display of coordinates, measure distances and areas, reverse geocode, and search for features by keyword or coordinates

- Advanced features include markup annotation and feature data query or filter

- Easily "mash-up" in the viewer other map services, such as keyhole markup language (KML), Web map service (WMS), ESRI's ArcGIS REST services, and Really Simple Syndication (RSS) feeds

- Alternately, use The National Map services with other popular viewers, such as Google Earth, Google Maps, and Microsoft Bing Maps using WMS, KML, or ArcGIS REST

- Visualize and discover The National Map data availability and product inventory status

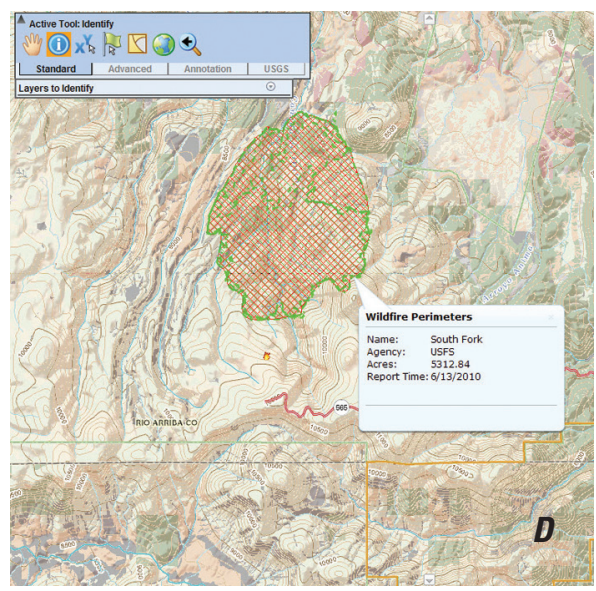

Figure 1. The National Map viewer $A$, uses easy to navigate foundational base maps; $B$, shows vintage of The National Map data inventory; $C$, makes it easy to download products such as the US Topo or The National Map data; and D, provides ways to add your data services to The National Map and make your own view. 


\section{Free Data Downloads From The National Map}

The National Map viewer is the new one stop destination for downloading all the latest The National Map data and products, including the following:

- Raster data: Orthoimagery, Elevation, Land Cover

- Vector data: Hydrography, Geographic Names, Transportation, Structures, and Governmental Units

- Map products: US Topo, Scanned Historic Topographic Maps

The National Map receives thousands of free download order requests weekly, and is committed to continuous improvement of The National Map services.

\section{Steps To Download Data From The National Map Viewer}

1. Zoom and pick your area of interest

2. Click the "Download Data" button

3. Select how to clip your data-by reference areas or viewable map extent

4. Select your themes and formats

5. For themes with multiple products, pick your products and preview to determine product coverage

6. Add the item to your cart and get more products by repeating these steps

7. When you have selected all the desired products, click "Checkout"
8. Enter your e-mail address to receive your order confirmation and click "Place order"

9. For raster or prepackaged map products, open the e-mail and click on the link for the product to begin extraction immediately

10. For vector products, a second e-mail will arrive within hours with a link and download instructions for the products requested

\section{By Robert M. Dollison}

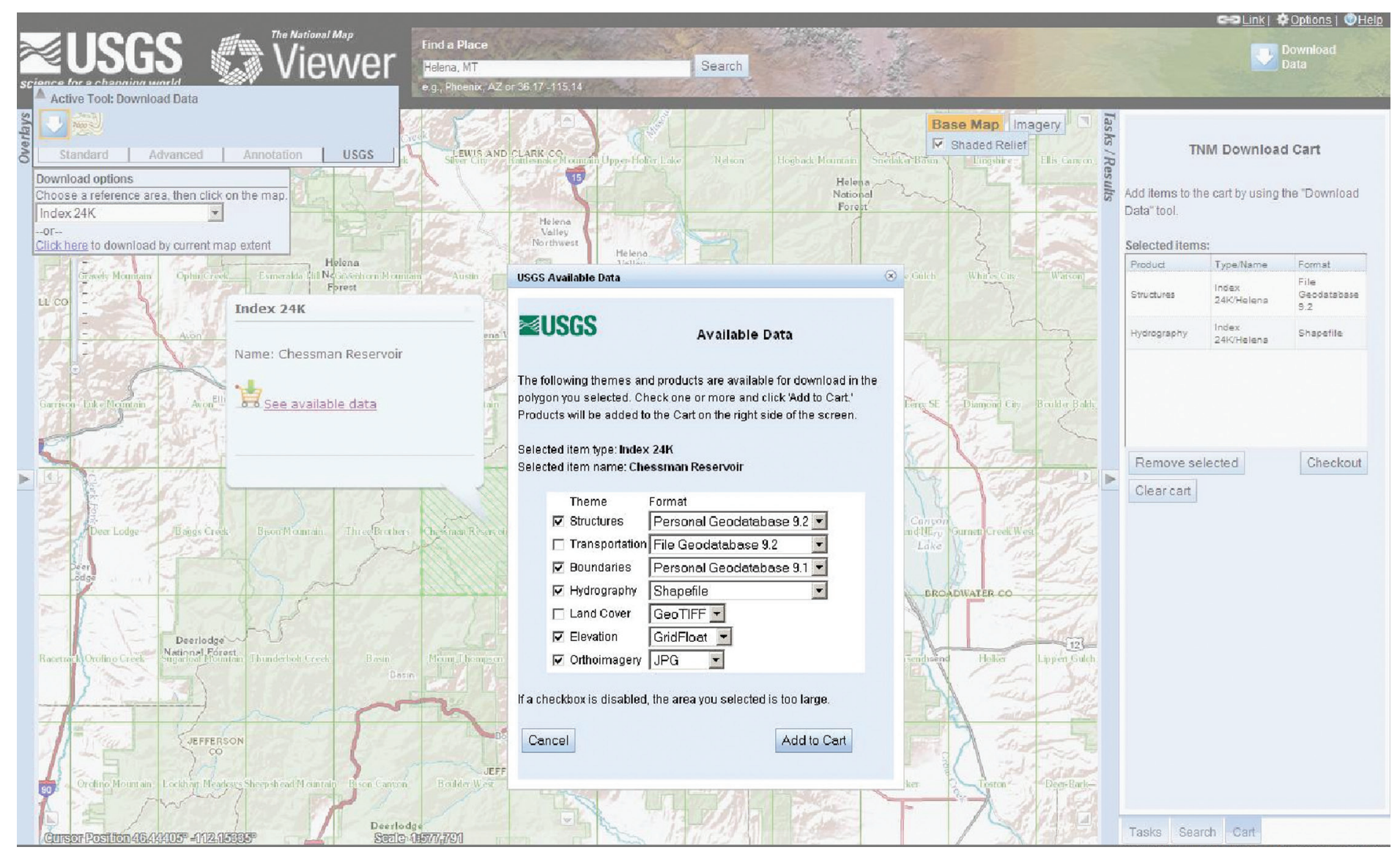

Figure 2. The National Map Viewer supports downloading all the latest The National Map data and map products—such as US Topo, Imagery, Elevation, and Hydrography-from one location. 